\title{
Surgical treatment of patients with primary hyperparathyroidism with a risk of hypercalcaemic crisis
}

\author{
Grzegorz Buła, Grzegorz Kowalski, Henryk Koziołek, Dominika Żądło, Adam Bednarczyk, \\ Adam Buła, Agata Gawrychowska, Jacek Gawrychowski
}

Department of General and Endocrine Surgery, Faculty of Medical Sciences in Zabrze, Medical University of Silesia, Katowice, Poland

\begin{abstract}
Introduction: The objective of the work was to evaluate the effectiveness of surgical treatment in patients with a high risk of hypercalcaemic crisis due to primary hyperparathyroidism (PHPT) and to determine the best time to undergo surgery.

Material and methods and Results: Between 2010 and 2019, 627 patients underwent surgery due to PHPT. Sixty-two patients (9.9\%) (47 women and 15 men, aged 28-79 years, average 53.7 years) faced the threat of a parathyroid crisis. In these patients, the average parathyroid hormone (PTH) levels were $774.02 \mathrm{pg} / \mathrm{mL}(95 \%$ CI: 203-1246 pg/mL) and ionised calcium (iCa2+) $1.91 \mathrm{mmol} / \mathrm{L}(95 \% \mathrm{CI}$ : $1.70-2.2 \mathrm{mmol} / \mathrm{L})$. The PTH postoperative concentration averaged at $37.86 \mathrm{pg} / \mathrm{mL}$ (95\% CI: 9.91-42.7 pg/mL) and iCa2 $+1.11 \mathrm{mmol} / \mathrm{L}$ (95\% CI: $1.07-1.21 \mathrm{mmol} / \mathrm{L}$ ). Bilateral neck exploration was performed in all patients with the removal of the affected parathyroid gland and biopsies of other parts. Histopathological examination revealed adenoma in 42 cases $(67.7 \%)$, hyperplasia in 16 (25.7\%), and parathyroid cancer in four of the patients $(6.6 \%)$. Comparison of tests before and after surgery showed a statistically significant decrease in PTH $(\mathrm{p}<0.001)$ and $\mathrm{iCa}(\mathrm{p}<0.001)$ in blood serum.

Conclusions: A developing hypercalcaemic crisis in the course of hyperparathyroidism is an indication for preoperative intensive medical therapy, along with urgent surgical intervention and removal of diseased parathyroid glands.

This type of surgery should be performed as soon as possible, even if there are no imaging tests, only based on an assessment of the general condition of the patient and their serum calcium levels. (Endokrynol Pol 2020; 71 (5): 392-396)
\end{abstract}

Key words: hyperparathyroidism; primary; surgery; hypercalcaemic crisis; parathyroidectomy

\section{Introduction}

Hypercalcaemic crisis is a life-threatening condition resulting from metabolic disorders related to excessive calcium levels in the blood serum [1-3]. This condition affects the function of many organs and systems, including kidneys, as well as central nervous, circulatory, and digestive systems. The main symptoms of a developing hypercalcaemic crisis include progressive polydipsia, polyuria, progressive signs of dehydration with confusion and anxiety, and excessive sleepiness and coma [4-6]. The exacerbation of bone pains as well as gastrointestinal complaints in the form of a peptic ulcer disease or pancreatitis, cardiac arrhythmia, or other cardiac problems are observed [7-9]. In the vast majority of cases (approximately 90\%), hypercalcaemia occurs during PHPT and cancer, often accompanied by dehydration. An excessive supply of calcium, the use of certain medications (vitamin A and D supplements, thiazides, oestrogens, or lithium salts), and some medical conditions (kidney damage, thyrotoxicosis, adrenal insufficiency, pheochromocytoma, or familial hypercalciuria) rarely result in hypercalcaemia $[5,10]$.

The treatment of hypercalcaemic crisis is difficult and complex, and the key to success is the elimination of the factor leading to its occurrence as soon as possible, including early diagnosis and surgical treatment of PHPT.

\section{Objective of the work}

The goal of the study was to evaluate the effectiveness of surgical treatment in patients at risk of hypercalcaemic crisis in PHPT and to establish the best time to undergo surgery.

\section{Material and methods}

Between 2010 and 2019, 627 patients underwent surgery due to PHPT. Of this group, 62 patients $(9.9 \%)$ were admitted as a matter of urgency due to symptoms related to developing parathyroid crisis. In all these patients, despite previous pharmacological treatment (fluid therapy, diuretics, and bisphosphonates), the concentration of ionised calcium in blood serum exceeded $1.7 \mathrm{mmol} / \mathrm{L}$. In addition to $\mathrm{Ca} 2+$, serum PTH and creatinine levels were deter- 
mined on ingestion, and the glomerular filtration rate (GFR) was calculated. The group consisted of 47 women (75.8\%) and 15 men $(24.2 \%)$ aged $28-79$ years, average 53.7 years. The location of the changed parathyroid glands in $56(90.3 \%)$ patients was based on urgent MIBI-SPECT scintigraphy or preoperative ultrasound. In the majority of patients, parathyroid scintigraphy was performed electively in the course of the disease, while in the remaining six patients $(9.7 \%)$ the clinical picture indicated the need for surgical intervention based on ionised calcium and PTH tests in blood serum and ultrasound imaging tests of the neck. All patients had a daily diuresis card and water balances.

Bilateral neck exploration was performed in all of the patients under tracheal general anaesthesia, identifying all parathyroid glands. The effectiveness of surgical treatment was confirmed by intraoperative assessment of PTH concentration in peripheral blood serum 20 minutes after parathyroidectomy (PTX). A statistical analysis was performed based on the Statistica 13.1 program with the calculation of arithmetic means, standard deviation, application of the Wilcoxon test, and a statistical significance assessment.

\section{Results}

In the group of 62 patients with a threatening parathyroid crisis, the average preoperative serum PTH level was 774.02 (95\% CI: 203-1246 pg/mL) and the average concentration Ca2 + 1.91 (95\% CI: 1.70-2.20 mmol/L) (Tab. 1).

Table 2 shows a comparison of clinical symptoms and additional diseases in the group of patients treated for PHPT, including those with a threatening hypercalcaemic crisis. The occurrence of urolithiasis, chronic renal failure, instances of consciousness or drowsiness, as well as acute pancreatitis in patients with threatening hypercalcaemic crisis should be emphasised. In all patients, after the introduction
Table 1. Threat of hypercalcaemic crisis in 62 patients operated on in 2010-2019 due to various forms of hyperparathyroidism

\begin{tabular}{|c|c|}
\hline \multicolumn{2}{|c|}{ Group of patients at risk of hypercalcaemic crisis } \\
\hline Age [years] & $28-79(53.7)$ \\
\hline \multicolumn{2}{|l|}{ Gender (n) } \\
\hline M & $15(24.2 \%)$ \\
\hline $\mathrm{F}$ & $47(75.8 \%)$ \\
\hline \multicolumn{2}{|l|}{ Cause of PHPT (n) } \\
\hline Adenoma & $42(67.7 \%)$ \\
\hline Hyperplasia & $16(25.7 \%)$ \\
\hline Carcinoma & $4(6.6 \%)$ \\
\hline Size of parathyroid gland [mm] & $20-51(35)$ \\
\hline \multicolumn{2}{|l|}{ PTH [pg/mL] } \\
\hline Before operation & $203-1246(774.02)$ \\
\hline After operation & $9.91-42.7(37.89)$ \\
\hline \multicolumn{2}{|l|}{ iCa2 + [mmol/L] } \\
\hline Before operation & $1.7-2.2(1.91)$ \\
\hline After operation & $1,07-1,21(1.11)$ \\
\hline
\end{tabular}

PHPT — primary hyperparathyroidism; PTH — parathyroid hormone; iCA2+ — ionised calcium

of intensive combined fluid therapy (2500-3000 mL $0.9 \% \mathrm{NaCl}$ ) with the supply of furosemide along with potassium infusions, the symptoms stabilised with an increase in serum $\mathrm{Ca} 2+$ concentration and correction of electrolyte deficiencies.

The patients were operated by classical method with bilateral neck exploration. Total removal of the diseased

Table 2. Comparison of clinical symptoms in a group of 627 patients operated on due to primary hyperparathyroidism (PHPT) in 2010-2019 without and with a threat of hypercalcaemic crisis

\begin{tabular}{|c|c|c|c|}
\hline Clinical symptoms & $\begin{array}{c}\text { PHPT without threat } \\
\text { of hypercalcaemic crisis } \\
\text { (n = 565) }\end{array}$ & $\begin{array}{c}\text { PHPT with threat } \\
\text { of hypercalcaemic crisis } \\
\text { (n=62) }\end{array}$ & $\begin{array}{c}\text { Statistical variability } \\
\mathbf{p}\end{array}$ \\
\hline Musculoskeletal pain & $443(78.4 \%)$ & $30(62.9 \%)$ & 0.12 \\
\hline Hypertension & $273(48.5 \%)$ & $16(25.8 \%)$ & 0.104 \\
\hline Kidney stones & $213(37.9 \%)$ & $38(61.2 \%)$ & 0.002 \\
\hline Chronic renal failure & $80(14.3 \%)$ & $26(41.9 \%)$ & 0.001 \\
\hline Fatigue & $134(23.4 \%)$ & $45(72.6 \%)$ & 0.292 \\
\hline Acute dehydration & $0(0 \%)$ & $4(6.5 \%)$ & 0.121 \\
\hline Pathological fractures & $54(9.5 \%)$ & $8(12.9 \%)$ & 0.112 \\
\hline Gastric and/or duodenal ulcer & $63(11.1 \%)$ & $6(9.7 \%)$ & 0.016 \\
\hline $\begin{array}{l}\text { Disturbance of consciousness } \\
\text { or increased drowsiness }\end{array}$ & $0(0 \%)$ & $10(16.2 \%)$ & 0.001 \\
\hline Depression & $90(15.9 \%)$ & $0(0 \%)$ & 0 \\
\hline Acute pancreatitis & $45(7.9 \%)$ & $10(16.1 \%)$ & 0.001 \\
\hline Coronary artery disease & $29(5.1 \%)$ & $13(20.9 \%)$ & 0.037 \\
\hline No complaints & $53(9.4 \%)$ & $0(0 \%)$ & 0 \\
\hline
\end{tabular}




\section{A}

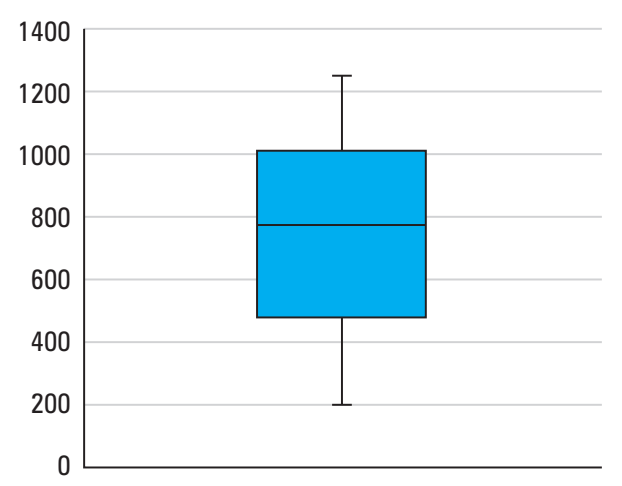

B

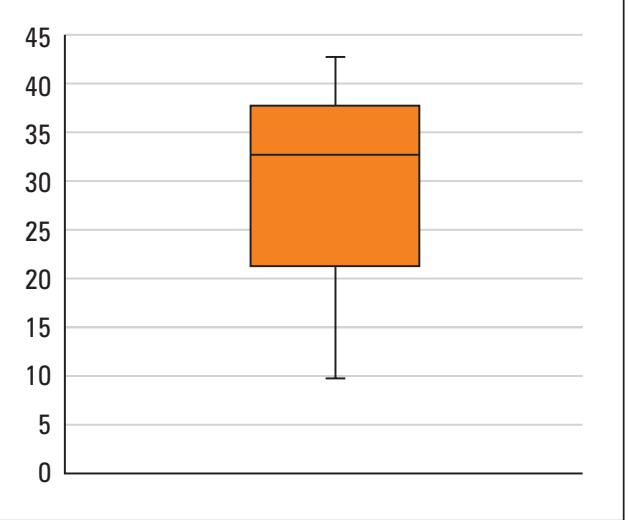

Figure 1. Pre-and postoperative serum parathyroid hormone concentrations in a group of patients with threatening hypercalcaemic crisis

A

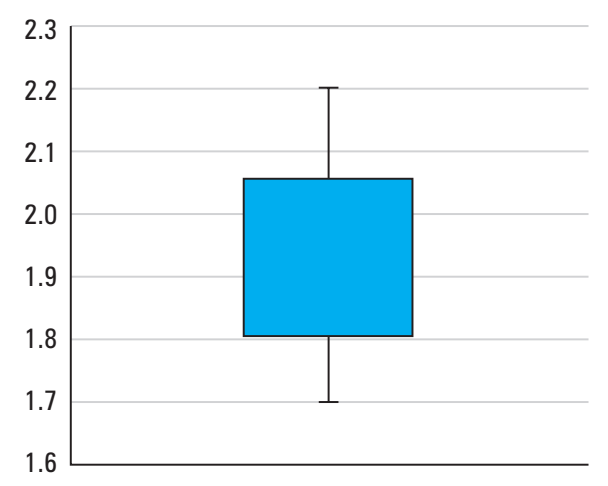

B

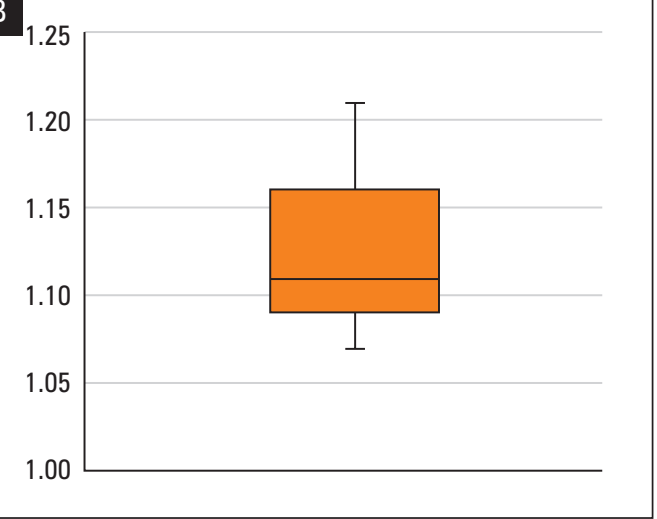

Figure 2. Pre- and postoperative serum calcium $(\mathrm{Ca2}+)$ concentration in a group of patients with threatening hypercalcaemic crisis

parathyroid with biopsy of the remaining glands was performed in all 62 patients. Eleven patients (17.7\%) also required a partial thyroid resection. Histopathological examination revealed 42 cases of adenoma $(67.7 \%), 16$ of parathyroid hyperplasia (25.7\%), and cancer in $6.6 \%$ of patients. The size of the diseased parathyroid glands ranged from 20 to $51 \mathrm{~mm}, 35 \mathrm{~mm}$ on average.

Post-operative examination of PTH in blood serum after resection of the diseased parathyroid glands compared to preoperative tests showed a statistically significant decrease $(\mathrm{p}<0.001)$ in its values - average 37.86 (CI: 9.91-42.7) pg/mL (Fig. 1). Also, the serum $\mathrm{Ca} 2+$ concentration showed a statistically significant decrease ( $\mathrm{p}<0.001)$ to mean values of 1.11 (95\% CI: 1.07-1.21) $\mathrm{mmol} / \mathrm{L}$ (Fig. 2). Intravenous calcium infusions were used in patients in the early postoperative course, gradually replacing them with oral substitution in combination with Vit D3 analogues. The treatment was carried out under water balance control with diuresis control, liquid therapy, and electrolyte equalisation.

In one patient after primary surgery for benign adenoma, signs of recurrent hyperparathyroidism were discovered. This patient required re-surgery combined with resection of the next parathyroid lesion with complete thyroidectomy. Histopathological examination revealed parathyroid carcinoma infiltrating the thyroid lobe. After two years, the patient was operated again due to the recurrence of hyperparathyroidism, recognising parathyroid cancer with dissemination to the surrounding tissues of the neck and mediastinum, and then undergoing additional radiation therapy. She is alive under oncological supervision.

\section{Discussion}

The clinical picture of PHPT is varied. In the foreground are complaints related to kidneys, as well as the urinary and skeletal systems. The disease is also manifested by gastrointestinal, cardiovascular, and nervous disorders $[7,8,11-13]$. The incidence and severity of individual ailments can vary and depends on serum calcium levels, critically increasing at levels exceeding $3.5 \mathrm{mmol} / \mathrm{L}[4$, 10] when the first symptoms of hypercalcaemic crisis manifest themselves. It is believed that the concentration of ionised calcium in blood serum is increasingly a leading criterion for hyper- and hypocalcaemia. Values 
above $1.7 \mathrm{mmol} / \mathrm{L}$ indicate a real threat of hypercalcaemic crisis.

According to literature data, the occurrence of hypercalcaemic crisis in the course of hyperparathyroidism relates to about $1.6-6 \%$ of patients [10]. Our own observations show a slightly higher percentage of patients at risk of its occurrence. The emerging metabolic disorders resulting from dyselectrolitaemia, manifested at particularly high calcium levels, accompanied by hypertonic dehydration leading to prerenal renal failure and features of metabolic acidosis, mean that hypercalcaemic crisis should be treated as a life-threatening condition. As shown by our own observations, most of them adapt to existing electrolyte disturbances due to long-term progress of the disease. Rapidly growing hypercalcaemia, which leads to rapid body decompensation, is extremely dangerous $[4,5,13]$. In addition to the initially occurring polyuria and vomiting and in the final stage of oliguria, there is, among heart rhythm disorders combined with bradycardia, a significant increase in body temperature and often the features of acute pancreatitis, to symptoms of shock manifesting as multi-organ failure, consciousness disorders, and coma $[8,13,14]$. Ultimately, this can lead to the death of the patient.

The dramaturgy of symptoms and the turbulent clinical course make it extremely important to prevent the development of hypercalcaemic crisis in the course of hyperparathyroidism and lowering serum calcium $[14,15,21]$. These activities should include the preparation of the patient for surgery as soon as possible, with the aim of removing the diseased parathyroid gland as a factor generating hypercalcaemia and the sequence of metabolic disorders resulting from it [16]. A proper preparation of the patient for surgery, safety of anaesthesia, and the effectiveness of the surgical treatment often require interdisciplinary cooperation and combined efforts of an internist, nephrologist, endocrinologist, anaesthesiologist, and surgeon [5, 6, $15,17,18]$. A clinical analysis of our patients indicates that it is not always possible to perform a MIBI parathyroid scintigraphy test, either because of the lack of technical capabilities or, above all, the rapidly worsening condition of the patient with a systematically increasing serum iCa2 + concentration. This concerned six patients $(9.7 \%)$ operated on by us.

Preoperative pharmacological treatment in patients with severe hypercalcaemia initially includes intensive hydration using isotonic sodium chloride solution [10, 22]. After the correction of fluid deficiencies, the treatment is continued in combination with loop diuretics and simultaneous correction of potassium and magnesium deficiencies. Our experience shows that this often effectively reduces calcium levels in the patient's blood serum and prevents their further increase. It also allows the avoidance of emergency surgery and instead an urgent elective procedure, which, in the absence of previous diagnostic and localisation tests, also gives time to perform them and increases the effectiveness of the surgical treatment. This is all the more important because, as a rule, the patient's serious condition and the resulting loads representing a high risk of perioperative complications, including death, require that the surgical treatment be effective $[6,10,11]$. According to our own observations, giant parathyroid adenomas are a common cause of critically high hypercalcaemia, which is a threat of breakthrough, although the literature data do not indicate a simple relationship between the size and activity of the diseased parathyroid glands. Additionally, the possibility of a malignant tumour originating from parathyroid glands should always be considered $[19,21,22]$. The presence of goitre and the occurrence of nodular changes in the thyroid gland may significantly impede the identification of both pre- and intraoperative diseased parathyroid glands [20]. It requires simultaneous thyroid resection, which took place in 11 of our patients (17.7\%), including unilateral "en block" lobectomy with suspected neoplastic changes. The effectiveness of surgical treatment should be confirmed by intraoperative PTH determination after resection of the affected parathyroid gland. The usefulness of these determinations was observed in the above-mentioned patients.

Both our own observations and the experience of other authors point to the effectiveness of surgery in the treatment of hypercalcaemia, which is a pre-breakthrough state, and a rapid post-operative improvement in the general condition of patients [2, 6, 16-18]. Continuous monitoring of patients plays an extremely important role in postoperative management.

\section{Conclusions}

A developing hypercalcaemic crisis in the course of hyperparathyroidism is an indication for preoperative intensive medical therapy, as well as urgent surgical intervention and removal of diseased parathyroid glands.

This type of surgery should be performed as soon as possible, even if there are no imaging tests, based only on an assessment of the general condition of the patient and their serum calcium levels.

\section{References}

1. Agarwal A, Singh D, Gupta S, et al. Primary hyperparathyroidism presenting as hypercalcemic crisis: Twenty-year experience. Indian J Endocrinol Metab. 2015; 19(1): 100, doi: 10.4103/2230-8210.131763, indexed in Pubmed: 25593835.

2. Lew J. Long-term Results of Parathyroidectomy for Hypercalcemic Crisis. Arch Surg. 2006; 141(7): 696, doi: 10.1001/archsurg.141.7.696, indexed in Pubmed: 16847243. 
3. Wang CA, Guyton S. Hyperparathyroid Crisis. Ann Surg. 1979; 190(6): 782-790, doi: 10.1097/00000658-197912000-00019, indexed in Pubmed: 518179.

4. Kasperk C. Hyperkalzämische Krise und hypokalzämische Tetanie. Internist (Berl). 2017; 58(10): 1029-1036, doi: 10.1007/s00108-017-0311-3, indexed in Pubmed: 28835974.

5. Gellert R. Hipo-i hiperkalcemia - patogeneza i problemy terapeutyczne. Forum Nefrologiczne. 2011; 4: 373-382.

6. Dąbrowska A, Tarach J, Zwolak A. Pierwotna nadczynność przytarczyc $\mathrm{w}$ przebiegu raka przytarczyc - wyzwanie diagnostyczne i terapeutyczne. Endokrynol Pol. 2015; 66(2): 150-167, doi: 10.5603/ep.2015.0023, indexed in Pubmed: 2593104.

7. Jacob JJ, John M, Thomas N, et al. Does hyperparathyroidism cause pancreatitis? A South Indian experience and a review of published work. ANZ J Surg. 2006; 76(8): 740-744, doi: 10.1111/j.1445-2197.2006.03845.x, indexed in Pubmed: 16916398.

8. Agarwal A, George RK, Gupta SK, et al. Pancreatitis in patients with primary hyperparathyroidism. Indian J Gastroenterol. 2003; 22(6): 224-225, indexed in Pubmed: 15030035.

9. Brown TC, Healy JM, McDonald MJ, et al. Heart block and acute kidney injury due to hyperparathyroidism-induced hypercalcemic crisis. Yale J Biol Med. 2014; 87(4): 563-567, indexed in Pubmed: 25506288.

10. Wieliczko M, Staszków M, Matuszkiewicz-Piwońska J. Approach to a patient with the hypercalcemic crisis. Nephrol Dial Pol. 2013; 17: 116-117.

11. Lowell A, Bushman N, Wang X, et al. Assessing the risk of hypercalcemic crisis in patients with primary hyperparathyroidism. J Surg Res. 2017; 217: 252-257, doi: 10.1016/j.jss.2017.06.041, indexed in Pubmed: 28711370.

12. Shah VN, Bhadada SK, Bhansali A, et al. Influence of age and gender on presentation of symptomatic primary hyperparathyroidism. J Postgrad Med. 2012; 58(2): 107-111, doi: 10.4103/0022-3859.97171, indexed in Pubmed: 22718053.

13. Gurrado A, Piccinni G, Lissidini G, et al. Hypercalcaemic crisis due to primary hyperparathyroidism - a systematic literature review and case report. Endokrynol Pol. 2012; 63(6): 494-502, indexed in Pubmed: 23339009.

14. Starker L, Björklund $\mathrm{P}$, Theoharis $\mathrm{C}$, et al. Clinical and Histopathological Characteristics of Hyperparathyroidism-induced Hypercalcemic Crisis. World J Surg. 2010; 35(2): 331-335, doi: 10.1007/s00268-010-0840-6, indexed in Pubmed: 21042912.

15. Phitayakorn R, McHenry C. Hyperparathyroid Crisis: Use of Bisphosphonates as a Bridge to Parathyroidectomy. J Am Coll Surg. 2008; 206(6): 1106-1115, doi: 10.1016/j.jamcollsurg.2007.11.010, indexed in Pubmed: 18501807

16. Ahmad S, Kuraganti G, Steenkamp D. Hypercalcemic Crisis: A Clinical Review. Am J Med. 2015; 128(3): 239-245, doi: 10.1016/j.amjmed.2014.09.030, indexed in Pubmed: 25447624.

17. Beck W, Lew J, Solórzano C. Hypercalcemic Crisis in the Era of Targeted Parathyroidectomy. J Surg Res. 2011; 171(2): 404-408, doi: 10.1016/j. jss.2011.04.010, indexed in Pubmed: 21658721.

18. Cannon J, Lew J, Solórzano C. Parathyroidectomy for hypercalcemic crisis: 40 years' experience and long-term outcomes. Surgery. 2010 148(4): 807-813, doi: 10.1016/j.surg.2010.07.041, indexed in Pubmed: 20800863.

19. Rutkowska J, Bandurska-Stankiewicz E, Matuszewski W, et al. Pierwotna nadczynność przytarczyc w ciąży - wyzwanie diagnostyczne i terapeutyczne. Endokrynol Pol. 2015; 66(3): 270-274, doi: 10.5603/ep.2015.0034, indexed in Pubmed: 26136136.

20. Gawrychowski J, Buła G. Imaging diagnostics for primary hyperparathyroidism. Endokrynol Pol. 2013; 64(5): 404-408, doi: 10.5603/ep.2013.0024, indexed in Pubmed: 24186598.

21. Gawrychowski J, Kowalski G, Buła G. Parathyroid Carcinoma - Diagnosis and Surgical Treatment a 24-year Experience. Pol J Surg. 2010; 82(2): 157, doi: 10.2478/v10035-010-0014-0.

22. Gawrychowski J, Kowalski G, Gawrychowska A. Parathyroid Cance - Occurrence, Diagnosis, Treatment. Pol J Surg. 2008; 80(9): 928-944, doi: 10.2478/v10035-008-0072-8. 